Toilets Can Work: Short and Medium Run Health Impacts of Addressing Complementarities and Externalities in Water and Sanitation Esther Duflo, Michael Greenstone, Raymond Guiteras, and Thomas Clasen NBER Working Paper No. 21521

September 2015

JEL No. I15,O13,Q53,Q56

\begin{abstract}
Poor water quality and sanitation are leading causes of mortality and disease in developing countries. However, interventions providing toilets in rural areas have not substantially improved health, likely because of incomplete coverage and low usage. This paper estimates the impact of an integrated water and sanitation improvement program in rural India that provided household-level water connections, latrines, and bathing facilities to all households in approximately 100 villages. The estimates suggest that the intervention was effective, reducing treated diarrhea episodes by $30-50 \%$. These results are evident in the short term and persist for 5 years or more. The annual cost is approximately US $\$ 60$ per household.
\end{abstract}

\author{
Esther Duflo \\ Department of Economics, E17-201B \\ MIT \\ 77 Massachusetts Avenue \\ Cambridge, MA 02139 \\ and NBER \\ eduflo@mit.edu \\ Michael Greenstone \\ University of Chicago \\ Department of Economics \\ 1126 E. 59th Street \\ Chicago, IL 60637 \\ and NBER \\ mgreenst@uchicago.edu
}

\author{
Raymond Guiteras \\ Department of Economics \\ 3114 Tydings Hall \\ University of Maryland \\ College Park, MD 20742 \\ guiteras@econ.umd.edu
}

Thomas Clasen

Rollins School of Public Health

Emory University

Grace Crum Rollins Building

1518 Clifton Road

Atlanta, Georgia 30322

and Faculty of Infectious and Tropical Diseases

London School of Hygiene and TropicDOO HAFIQH

Thomas.Clasen@1shtm.ac.uk 
Poor sanitation is widely considered a major obstacle to well-being in many parts of the world. An estimated 748 million people lack access to improved sources of water, and more than 2.5 billion lack improved sanitation (WHO - UNICEF 2014). In India, open defecation is still practiced by $65 \%$ of the rural population and only $14 \%$ of the rural population have piped-in water to the household (WHO - UNICEF 2014). By some estimates, lack of safe water, inadequate sanitation, and poor hygiene practices cause 1.1 million deaths from diarrhea each year, representing 1.5\% of the global burden of disease (Prüss-Ustün et al. 2014), similar to HIV-AIDS. Open defecation in India may be responsible for approximately $9 \%$ of total infant mortality, or 6.5 deaths per 1,000 infants per year (Geruso and Spears 2015).

This challenge to well-being has not gone unnoticed. Bill Gates talks of "reinventing the toilet" and has put the weight of his foundation behind this effort (Bill \& Melinda Gates Foundation 2011, Gates III 2012). Building on his 2013 campaign statement "pehle shauchalaya, phir devalaya” (“toilets first, temples later”), current Prime Minister Narendra Modi has launched the Swachh Bharat (“Clean India”) Mission, aimed at ending open defecation by 2019 (Times of India 2013, Modi 2014). Swachh Bharat proposes to provide toilets to all 110 million rural households that currently do not have one, at a cost of US\$22.0 billion (Ministry of Rural Development 2014, Ministry of Drinking Water and Sanitation 2014).

However, the evidence that increasing sanitation coverage alone in rural areas would reduce diarrhea and save lives is surprisingly thin. Infrastructure-based (i.e. connected to sewerage) solutions have proved effective in urban environments when combined with improvements in water supply (Cutler and Miller 2006, Galiani, Gertler, and Schargrodsky 2005). However, interventions promoting on-site sanitation without sewerage, as is typically implemented in rural and other low-density settings, have not been as effective as sewerage (Wolf et al. 2014). Two recent cluster-randomized trials evaluating sanitation-only interventions in rural India, one in Orissa (Clasen et al. 2014) and the other in Madhya Pradesh (Patil et al. 2014) find only modest impacts of latrine construction on latrine usage, and no impacts on health.

Part of the issue is that these sanitation-focused efforts have not fully taken on board two factors that play a key role in water and sanitation: complementarities and externalities. Epidemiological complementarities between water and sanitation interventions may arise because there are multiple pathways for transmission of water-borne disease (Clasen et al. 2007, Waddington and Snilstveit 2009). A behavioral complementarity can occur if providing water encourages latrine use - 
without convenient access to water, it may be difficult to keep a latrine clean, and poor maintenance may discourage use (Barnard et al. 2013). Furthermore, willingness to pay for the convenience of piped water in the home appears to be high (Devoto et al. 2012), in contrast to a low willingness to pay for improvements in water quality by itself (Kremer et al. 2011, Berry, Fischer, and Guiteras 2012) and latrines by themselves (Gupta et al. 2014, Patil et al. 2014). Externalities emerge because pathogens can re-contaminate water sources as long as any open defecation persists.

The design of sanitation interventions clearly reflects the importance of achieving near-universal use. For example, the most popular education effort, “community-led total sanitation” (CLTS) emphasizes eliminating open defecation completely from villages. Similarly, India's Total Sanitation Campaign included monetary incentives for leaders of villages that become "opendefecation free” (Spears 2012). However, interventions typically fall short of achieving high levels of use or eliminating open defecation (Barnard et al. 2013, Clasen et al. 2014, Patil et al. 2014, Gertler et al. 2015, Guiteras, Levinsohn, and Mobarak 2015), and interventions focused on sanitation alone clearly neglect complementarities across water and sanitation. Dealing with these two issues simultaneously would require significant infrastructure investment in rural areas, and the idea has typically been written off as un-realistically expensive: current approaches instead favor individual investment and behavior change interventions (Zwane and Kremer 2007, Perez et al. 2012, WHO - UNICEF 2014).

In this paper, we provide what we believe is the first piece of rigorous evidence on the impact of providing universal access within a village to hygienic latrines and in-home piped water at the same time, at a reasonable cost. The design of the program we evaluate takes externalities and complementarities seriously: Infrastructure is built to insure that every household in the village is connected to a local water and sanitation network, and every household is provided with a pourflush toilet and piped water, with taps in the home and the toilet. Villages are brought into the program only when they agree to pay a (subsidized) fee to connect $100 \%$ of the houses and to contribute to an endowment that will pay for maintenance and future additions. The system is turned on only when the work is completed. Mindful of the externalities, the NGO insists on 100\% participation among households in each village to ensure there is no slippage. The approach is uncommon but is not "gold plated": the program is run in rural Orissa, one of the poorest parts of India, using an elevated water tank and gravity, it costs only US\$ 60 per household per year. 
Three features of the program permit credible estimation of causal effects: first, in each village, piped water services were activated for all households at the same time, and sanitation coverage increased rapidly when that happens (see figure 1); second, the implementer collected monthly data on outcomes beginning two years or more before the activation of services and continuing for up to five years after - our primary outcome is doctor or nurse visits for diarrhea, for which there is a clear pathophysiological connection to clean water and sanitation; third, services were activated in different months in different villages. Together, these features permit the estimation of credible treatment effects, based on differences in outcomes before and after the sharp change in environmental conditions and controlling for village fixed effects, village-specific trends in outcomes, and month-by-year fixed effects. In addition, the long follow-up period provides a rare opportunity to test whether the effect persists in the medium run.

We find substantial reductions in water-related disease: episodes of severe diarrhea declined by 30-50\%. Impacts appear immediately and persist for at least five years, which is as long as the data

allow. Further, there is also evidence, albeit smaller in magnitude and estimated less precisely, of declines in the incidence of malaria and fever, for which there are possible pathophysiological relationships, although less direct than for diarrhea. These results show that comprehensive, if nofrills, water and sanitation infrastructure can significant reduce water-related morbidity in rural areas.

\section{Background}

\section{A. The Consequences of Clean Water and Sanitation for Human Health}

In this sub-section, we provide a brief overview of the basic biomedical science of water-related disease and the mechanisms by which clean water, sanitation and hygiene can improve health. Our discussion is based on Curtis, Cairncross, and Yonli (2000) and Cairncross and Valdmanis (2006), to which we refer the interested reader for more detail.

Many conditions fall under the designation of "water-related disease." The most common classification system for these diseases, the Bradley Classification (White, Bradley, and White 1972), organizes them by mode of transmission. These modes are:

- Waterborne: pathogen is ingested from drinking-water (includes fecal-oral diseases such as diarrhea and typhoid fever); 
- Water-washed: pathogen can be transmitted from person to person because of poor hygiene (includes fecal-oral diseases and skin and eye infections such as scabies and trachoma);

- Water-based: pathogen is transmitted by a host that lives in the water (includes schistosomiasis and guinea worm);

- Water-related insect vector: pathogen is transmitted by an insect that breeds in water (includes malaria and dengue).

These categories are clearly not mutually exclusive, since most fecal-oral diseases are both waterborne and water-washed. We focus on fecal-oral disease, diarrhea in particular, since reviews typically estimate that nearly $90 \%$ of deaths preventable by improvements to water, sanitation and hygiene are in the fecal-oral group (Prüss-Üstün et al. 2008). However, it is important to note that it is possible for changes in environmental conditions to affect any of these categories. For example, improvements in water supply could not only reduce waterborne disease by improving water quality, but also reduce water-washed disease by increasing water availability for personal hygiene, or reduce water-based disease if people no longer need to enter or approach water bodies to collect water themselves. Similarly, improvements in sanitation could reduce exposure to waterrelated insect vectors during open defecation.

The World Health Organization defines diarrhea as the passage of three or more loose or liquid stools per day, or more frequent passage than is normal for the individual (World Health Organization 2013). Diarrhea can be the result of several bacterial, viral or parasitic organisms. These specific diseases are classified together because of their similar symptoms and their shared mode of transmission: a pathogen in feces, usually human although occasionally animal, which is ingested by and causes infection in a new human host. There are several pathways for transmission, which are summarized in the famous F-diagram of Wagner and Lanoix (1958): pathogens enter the environment in feces, and are transmitted via fluids, fingers, flies, or field crops to a new host, either directly or through food. (See Figure A3 in the Appendix.) An important feature of this model is the distinction between primary and secondary barriers to transmission. Primary barriers are those that prevent feces and their associated pathogens from entering the environment. These include safe disposal of feces and removing fecal material from hands after defecation or contact with child's feces. Secondary barriers are those that stop pathogens that have entered the environment from reaching and infecting a new host. These barriers include protecting or treating 
water, handwashing and safe preparation and storage of food. Because most types of diarrheal disease resolve within two weeks (World Health Organization 2013), it is possible for the number of cases to respond quickly to changes in environmental conditions.

The F-diagram helps understand how various interventions and technologies could plausibly affect diarrheal disease. Sanitation can be effective if it prevents feces from entering the environment, which requires facilities that are technically adequate (i.e. isolate fecal matter from the water supply and other vectors such as flies) and are widely available and used. An improvement to water supply can affect several pathways: an increase in quantity and convenience can increase handwashing; treatment or source protection can operate as a secondary barrier by preventing pathogens from entering the water or removing or killing pathogens that have entered the water.

The F-diagram is also useful in making clear the interdependence of different interventions and behaviors (Eisenberg et al. 2012). In a community with a high load of fecal-oral pathogens and several modes of transmission, any intervention that blocks one transmission mechanism may have little effect on health on its own, but a combination of such interventions may be effective (PrussUstun et al. 2004). This is especially likely where levels of fecal-oral pathogens are high, since the relationship between dose and infection probability is likely to be relatively flat at high levels of exposure (Eisenberg et al. 2012). Alternatively, the effects of interventions could be independent, especially in places with intermediate pathogen levels (where the relationship between pathogen levels and infection is believed to be roughly log-linear (VanDerslice and Briscoe 1995)), where the interventions operate on independent mechanisms (Cairncross and Valdmanis 2006) and without significant feedback between transmission mechanisms (Eisenberg, Scott, and Porco 2007). Finally, it is even possible for interventions to be substitutes, especially in contexts where exactly one transmission mechanism is dominant, or where there is substantial overlap in the transmission mechanisms targeted by separate interventions.

The evidence on interdependence is scarce. Simulation studies suggest that complementarities, independence or substitution are all possible, depending on the context and interventions combined (Eisenberg et al. 2012, Eisenberg, Scott, and Porco 2007). Some observational studies have found evidence for positive interactions, in particular that the benefits of clean water are greater when sanitary conditions are good (VanDerslice and Briscoe 1995). However, meta-analyses have not detected systematically greater effects of combined interventions than individual interventions, 
although precision is limited by the small number of high-quality studies (Fewtrell et al. 2005, Clasen et al. 2007). To our knowledge, only one randomized trial, currently in the field, has explicitly randomized the interaction of water, sanitation and hygiene interventions (Arnold et al. 2013).

\section{B. The Rural Health and Environment Program}

This paper evaluates the Rural Health and Environment Program (RHEP), a village-level intervention that promotes adoption of household latrine and bathing facilities, a community water tank, and a distribution system that supplies piped water to household taps. RHEP was developed by Gram Vikas (GV), an Indian non-governmental organization, and implemented in villages in Orissa, one of the poorest states in India.

Pre-intervention water supplies consisted mainly of village ponds and open streams. Open defecation was the norm, as is typical of Orissa, where historically only $10 \%$ of the population has had access to safe water and sanitation (Government of India 2012). RHEP was first piloted in 5 villages (340 households) in 1992. It was then expanded in four phases, adding 40 villages (3,000 households) from 1995-1998, 27 villages (2,000 households) from 1999-2001, 38 villages (3,000 households) from 2001-2003 and 160 villages (8,000 households) from 2003-2006 (Gram Vikas 2001, 2005). We study the 96 villages from these four phases for which we can determine the exact month in which the water system was activated and from which a sufficient number of monthly observations of health outcomes were obtained. See Section II.B. for details on sample selection.

Because the timeline is important for the research design, we detail the typical sequence of events for implementing RHEP in a village (Gram Vikas 2001, 2004, 2005, Keirns 2007). First, GV extension workers identify a village well-suited to the program. Desirable characteristics are a strong sense of community and good village leadership. Next, GV representatives meet informally with village leadership. If there is interest in starting a program, a series of village meetings are held to build participation and obtain 100\% consensus for participation in the program. This process usually takes 3-6 months, but can take up to 18 months, in particular in villages with several caste groups that will need to share water and sanitation infrastructure. GV insists on $100 \%$ participation because of the strong externalities inherent in sanitation: if even a few villagers do not participate, they can transmit disease to their neighbors. 
Once the village has reached $100 \%$ consensus, GV and the village enter a formal agreement. At this time, data collection begins, along with construction. Villagers begin construction of household latrine and bathing facilities, using their own labor and locally acquired materials. Once all households in the village complete the external structures of their latrines and bathing houses up to the roof, GV subsidizes inputs the villagers cannot provide themselves, e.g. ceramics and piping materials. When completed, household facilities consist of a water-sealed pit latrine and a private bathing area, both enclosed by a masonry superstructure with roof and separate doors. ${ }^{1,2}$

The water supply system has several components. The first is a suitable water source, usually a protected dug well or a deep tube well. The second is a village overhead water tank, with a capacity of approximately 80,000 liters, and a pump to lift water from the well into the tank. The third is the gravity distribution system, which pipes water from the tank to individual households. Finally, three taps are installed for each household, one each for the latrine and bathing room and one inside the home. ${ }^{3}$ Villagers supply unskilled labor and locally available materials while GV provides skilled labor and specialized materials. Construction of the water supply requires 3-4 months of work, but usually takes one calendar year or more to complete because work is not continuous villagers usually supply their own labor outside of the planting and harvest seasons.

Although some households inevitably complete their sanitary houses sooner than others, GV does not activate the water supply until all sanitary facilities are complete. GV believes that households are primarily interested in getting running water for their home, and this is what leads them to agree to pay their share of the entire water and sanitation system. ${ }^{4}$ Furthermore, social pressure or cross-subsidization can help push lagging households towards completion, and these

\footnotetext{
${ }^{1}$ Latrines constructed during RHEP are pour-flush, consisting of a concrete squatting slab and a water seal (i.e. a U-pipe filled with water) with piping leading to a soak pit approximately 20 feet away from the slab. Typically, 1-3 liters of water are required for adequate flushing. The water seal blocks odors, which can discourage use, and flies, which can transfer pathogens. In almost all cases, RHEP uses a dual pit design, in which two pits are used alternately: the first pit is used until it fills, then it is sealed and a Y-junction redirects waste to the second pit. The first pit is left sealed for at least 12 months, until the waste can be safely removed. Each pit takes 3-5 years to fill (Keirns 2007). These latrines, if properly used and maintained, satisfy the standard WHO definition of "improved sanitation," in that they ensure hygienic separation of human excreta from human contact (WHO - UNICEF 2013).

2 The bathing facility - a simple 20 sq. ft. room with a tap and a drain - is somewhat unusual for a water and sanitation intervention. Because of the high prevalence of gynecological and skin diseases, GV, attributing these diseases to the need to bathe in the polluted waters of local ponds, deemed it important for women to have a private space and clean water for bathing.

${ }^{3}$ The use of a protected source and a piped household connection means that the level of service meets the WHO - UNICEF Joint Monitoring Programme’s highest standard, “piped connection on premises” (WHO - UNICEF 2013). In addition, the water is treated by periodically adding chlorine powder to the tank.

${ }^{4}$ The evidence of high willingness to pay for water at home is consistent with Devoto et al. (2012).
} 
forces would be muted if leading households received water service (Jenkins and Curtis 2005). Crucially for the research design, water service is activated suddenly and simultaneously for all households in the village. Sanitation coverage also increases rapidly, since access to piped water facilitates the use of the pour-flush toilets. Following construction, villagers are responsible for operational costs. GV provides some training for villagers to provide maintenance and advises village committees on governance, but does not provide further subsidies or other direct inputs.

Using GV records, we estimate that the total cost of implementing RHEP in a typical village of 50 households was approximately US\$60 per household per year, as compared to annual household consumption of approximately US\$740. Of this \$60 annual cost, we estimate that annual maintenance costs are about $\$ 11$ with the annuitized value of the upfront capital cost accounting for the remainder. Details of this calculation, which includes the value of villagers' labor, Gram Vikas personnel time and external subsidy, are provided in the Appendix.

\section{Data and Sample Selection}

\section{A. Data}

The implementation and outcome data were obtained from GV's internal "Monthly Progress Reports” (MPRs). MPRs are compiled on a monthly basis by GV personnel, either during monthly (or more frequent) visits or by GV staff residing on-site. MPRs contain detailed information on the status of RHEP (e.g. water tank construction, number of households with and without completed latrine and bathing facilities, number of households using their latrine), allowing exact identification of the month in which water improvement begins. Outcome data are recorded each month by the GV village supervisor, who draws on a variety of sources, including monthly or more frequent visits to individual households, consultation with the local health clinic (when one exists), and the village health committee. The data collection starts as soon as a village is enrolled in the program, well before the construction is finished.

It is important to note that diarrhea episodes are only recorded if a resident is "checked" or "treated." "Checked” means that the villager went for a consultation with a medical professional, i.e. a health worker or a doctor. "Treated" means that the villager received treatment for the condition, again from either a health worker or a doctor. This excludes cases for which a villager does not seek a medical consultation, or cases when a villager seeks treatment via home remedies 
or local healers. As a result, our measures underestimate the overall morbidity associated with diarrhea, but are likely to represent more severe cases that are more highly correlated with mortality and serious sequelae (Kotloff et al. 2013). This outcome may also be less susceptible to courtesy bias than caretaker reporting, which is the measure most frequently used in assessing the impact of environmental interventions on diarrhea (Schmidt et al. 2011). This is particularly important in our case since the data is maintained by GV. We focus on the "treated" measure in our analysis but the results using the "checked" variable are similar. ${ }^{5}$

\section{B. Sample Selection}

A village is included in the analysis if the month in which the water supply is activated can be identified. There are 96 such villages, with approximately 5,500 village-by-month observations total. The average village contains approximately 90 households and 500 residents. We use $\tau$ to indicate the month relative to the month in which the water switches on, so $\tau=-1$ is one month before the water turns on, $\tau=0$ is the month the water turns on, $\tau=1$ is one month after, etc.

We analyze three samples. Sample A includes all observations with known $\tau$, i.e. all observations from villages in which the month of water supply activation is known. Sample B uses only observations from 2 years prior to 5 years after the activation of the water supply, i.e. $\tau \in\{-24,-23, \ldots,+59\}$, and includes only villages for which there are at least six observations before and six observations after the activation of the water supply. Sample $\mathrm{C}$ uses only observations within one year of activation of the water supply, i.e. $\tau \in\{-12,-11, \ldots,+11\}$, and includes only villages with observations in at least six of the 12 months before and six of the 12 months after activation. The tradeoffs among the samples are between sample size (largest in Sample A) and using a sample closer to a balanced panel (closest in Sample C).

Table 1 provides descriptive statistics. In Figure 1, we show the rapid improvement in environmental conditions. Among villages in Sample B, the median share of households using a

\footnotetext{
${ }^{5}$ Other diseases monitored include malaria, fever, typhoid, jaundice, cold and cough, night blindness, scabies, TB and leprosy. We do not focus on these because they are either too scarce for any reasonably-sized treatment effect to be detected, are not consistently collected, or are only weakly or indirectly related to water and sanitation conditions. Similarly, data are recorded on mortality and child mortality, but given the rarity of these events, we do not have statistical power to detect any reasonably-sized effect. We did detect an association between the initiation of services and a reduction in malaria, which we discuss in Section IV.C.
} 
latrine increases from less than 0.2 six months before water services are activated to over 0.9 just three months after. ${ }^{6}$ Similarly, no villages had piped water before the water tank was activated, but full piped water service in $93.9 \%$ of village-month observations in the post-intervention period.

The patterns in Figure 1 mean that the period that begins with $\tau=0$ can be used to determine the impact of a combined water and sanitation intervention that accounts for complementarities and externalities. Precision issues preclude definitive statements, but the months immediately preceding $\tau=0$ when the usage rate of latrines was increasing rapidly (recall Figure 1) can be used to qualitatively assess whether latrines by themselves (i.e., without access to piped water) affect morbidity rates. A comparison of these months with the months after water is turned on provides a sense of the importance of complementarities in water and sanitation interventions.

\section{Econometric Methods and Empirical Results}

\section{A. Empirical Strategy}

We start by presenting the results from an unrestricted event study, estimating

$$
y_{v t}=\sum_{s=-12}^{+11} \alpha^{s} \tau_{v s}+c_{v}+c_{t}+\varepsilon_{v t},
$$

where $y_{v t}$ denotes the outcome of interest, i.e. monthly cases of treated diarrhea, for village $v$ in month $t, \tau_{v s}$ is an indicator for the $s^{\text {th }}$ month after the water improvement begins (starting at zero, i.e. $\tau=0$ is the month in which the water turns on) in village $v, c_{v}$ is a fixed effect for village $v$, $c_{t}$ is a fixed effect for year-by-month $t$ and $\varepsilon_{v t}$ is the disturbance term for village $v$ in month $t$. The $\tau_{v,-1}$ indicator is omitted, so estimates of the coefficients $\alpha^{s}$ are interpreted as the mean of the outcome variable relative to the month before the water supply is activated.

The village fixed effects $c_{v}$ control for any time-invariant mean differences across villages, whether from observable or unobservable confounders. Multiple observations in each month from different villages allows for the estimation of month-by-year fixed effects $c_{t}$, which control for aggregate monthly shocks (e.g., due to weather) across villages in the sample. Because the

\footnotetext{
${ }^{6}$ The sample in Figure 1 is additionally restricted to villages with at least 6 observations of latrine coverage and the operational status of the water tank both before and after the activation of services.
} 
intervention occurred in different months in different villages, it is possible to separately identify the program and time effects.

Most important, the combination of (a) the sudden change in the availability of water in month $\tau_{v, 0}$ and sanitation in the surrounding months and (b) the possibility of a rapid response of diarrhea to a change in the environment together give a sharp prediction of a swift change in the number of diarrhea cases. In terms of the econometric model, this prediction is of negative values of $\alpha^{1}, \alpha^{2}$ , etc. Since there are relatively few observations for each $\tau$ and no restrictions are imposed on the month-by-month effects, these estimates are unlikely to be very precise. However, this regression will be informative about the integrity of the research design, since it allows for visual inspection of pre-program trends that could cause bias. Further, it permits visual examination of the evolution of any treatment effects and informs the choice of econometric model to summarize them (e.g., mean shift versus mean shift plus trend break).

Motivated by the results of fitting equation (1), we fit the following equation:

$$
y_{v t}=\alpha \operatorname{POST}_{v t}+c_{v}+c_{t}+\varepsilon_{v t},
$$

where $\operatorname{POST}_{v t}$ indicates that the water supply has turned on in village $v$ in month $t$, and all other variables are as in equation (1). This collapses the month-by-month estimates from equation into a single summary measure of the program's impact. For example, in Sample C, $\hat{\alpha}$ represents an estimate of the program's impact in the first year, relative to the mean in the year leading up to the activation of services.

We also estimate two key variants of equation (2). In the first, we add a village-specific time trend $\varphi_{v} c_{v} \tau_{v t}$. This separates the impact of the program from other ongoing trends, to the extent that these trends are roughly linear. However, this would not adequately control for other programs or behaviors that switch on abruptly and simultaneously with RHEP. We revisit this possibility below. In the second, we test for the persistence of program effects by separating the POST $_{v t}$ indicator into two indicators for sub-periods, $1\left\{0 \leq \tau_{v t}<36\right\}$, i.e. the first three years of the program, and $1\left\{\tau_{v t} \geq 36\right\}$, the period beyond three years.

In all regressions, the standard errors are clustered at the village level (Bertrand, Duflo, and Mullainathan 2004). Each village-by-month observation is weighted by the inverse of the number 
of observations on that village, so that each village receives equal weight in the estimation. The results are insensitive to alternative weighting strategies, as described below and in the appendix.

\section{B. Results}

Several key findings are evident in Figure 2, which plots point estimates and 95\% confidence intervals for $\alpha^{-12}, \alpha^{-11}, \ldots, \alpha^{+11}$ in equation (1) for Sample C. First, although it is demanding of the data to estimate separate event study coefficients for each month, the downward shift after the water turns on is evident visually. Second, the post-treatment effect appears roughly constant over time, suggesting that a mean shift model is appropriate. Third, there is no noticeable downward trend prior to the start of improved water, which supports the validity of the research design. Fourth, although latrine coverage increased in the months immediately preceding the activation of water (see figure 1), there is no observable reduction in diarrhea in these months. That is, increases in latrine coverage that did not achieve near-universal coverage and were not accompanied by piped water did not have immediate effects on diarrhea.

Figure 3 plots the results of a similar exercise, this time including indicators for each of the 24 months prior to and each of the 60 months following the initiation of services. This is the result of estimating equation (1) with sample B.

The results are similar: there is a discernable improvement after the water supply is activated and no pre-intervention trend is visible. Furthermore, this improvement persists with similar magnitude for the full five years post water activation. The monthly estimates become less precise over time, because the number of observations that identify the treatment effect declines several years after activation.

Table 2 reports results from the estimation of equation (2), summarizing the program's overall impact. There are large and statistically significant reductions across all three samples. Estimates of the effect on the number of cases per village-month range from -0.45 , relative to a preintervention mean of 1.18 (Sample C), to -0.59, relative to a pre-intervention mean of 1.08 (Sample A). The lower panel reports estimates after adjustment for village-specific linear trends and shows that the results are robust.

Table 3 reports on formal tests of the persistence of the program's effect. The evidence for persistence is strong: while the point estimates for diarrhea are somewhat smaller in absolute value in the period $\tau_{v t} \geq 36$ than in the period $0 \leq \tau_{v t}<36$, the null hypothesis that the two estimated 
coefficients are equal is not rejected in either sample (p-value $\approx 0.3$ ). Further, the estimate for the latter period is still economically and statistically significant.

We tested the robustness of these findings by repeating the analysis using different specifications (i.e., different weighting schemes, additional fixed effects, and different sample selection criteria), alternative definitions of key variables (i.e., activation of water supply and diarrhea checked rather than treated), and choices made in cleaning the data. Results of these robustness checks are summarized in Figure 4. Exact results vary, but the pattern of statistically and economically significant health improvements is robust: in 14 of 16 specifications, the estimate is significant at the 95\% level. Further details are provided in Section A1 of the Appendix.

\section{Threats to validity}

This subsection discusses threats to validity of the paper’s primary results.

Identification assumption.- - This paper's identification assumption is that no other determinants of diarrheal disease change abruptly and at the same time as the activation of water and sanitation. One potential threat to this assumption is that GV works with RHEP villages on other projects, such as building schools, skills training, aquaculture and sustainable forestry. However, these programs are unlikely to cause bias, because their timing is not coordinated with activating the water supply and they are implemented more gradually. Furthermore, our results are robust to the inclusion of village-specific linear time trends in the regression analysis, which absorb the impact of these other programs to the extent that they arrive gradually and have approximately linear effects on outcomes over time.

Data collection.-This study relies on outcome data collected by the implementer and not independently verified. The implementer may have incentives to exaggerate the beneficial impact of the project. While we cannot rule out bias entirely, several considerations mitigate this possibility. First, the purpose of the data was to provide information on the project's implementation and conditions in the village to help GV's programming. GV did not collect these data for an evaluation, as evidenced by the fact that they had not previously been used in this way, despite having been collected for many years. In fact, the paper forms were locked in a closet when they were uncovered by the research team during a visit to discuss an unrelated evaluation (Hanna, Duflo, and Greenstone 2014). Second, GV personnel were not compensated on the basis of the 
outcome, and were subject to sanction for misreporting. Third, and perhaps most importantly, the focus is on cases for which treatment was sought or received, which is more easily verifiable data.

Observed reduction in malaria.--Our analysis also finds an association between the initiation of services and a reduction in reported cases of malaria. Table 4 presents the results of estimating equation (2) using cases of malaria treated as the dependent variable (columns (1)-(3)). The effect sizes, relative to the pre-intervention means, are slightly smaller than the effects found on diarrhea, but are economically important and statistically significant. Robustness checks are provided in Section A2 and Figure A1 of the Appendix. Because there is no direct biological mechanism linking clean water and malaria, this finding could indicate reporting bias that would in turn raise doubts about the validity of the estimated impact on diarrhea. Our ability to conduct placebo tests is limited by the fact that Gram Vikas's data-collection efforts naturally focused on water-related diseases. However, data were regularly collected on tuberculosis, which is not plausibly waterrelated, and we do not find any significant effect on cases of tuberculosis, although precision is limited. See Tables A2 and A3 in the Appendix.

Alternatively, the improved sanitation program may have reduced the incidence of malaria through an indirect channel. First, in-home water and on-site toilets may reduce exposure to malaria vectors, since such exposure can occur during trips for open defecation, water collection, or bathing or washing clothes in local ponds (Keiser, Singer, and Utzinger 2005). Second, malaria is endemic in the area. A reduction in diarrheal disease reduces insults to immune function, which could in turn reduce co-morbidity from other infectious diseases (Schmidt et al. 2009, Walker and Black 2009). A related possibility is that the intervention may have reduced cases of fever misreported as malaria: since malaria is not often diagnosed rigorously, many reported cases could in fact be fever caused by water-borne infections (Cohen, Dupas, and Schaner 2014). Consistent with this hypothesis, when we estimate equation (2) using cases of fever treated as the dependent variable (columns (4)-(6) of Table 4), we observe an economically large, although generally statistically insignificant, association of a reduced number of cases of fever with the initiation of program services. Robustness checks are provided in Section A2 and Figure A1 of the Appendix. 


\section{Conclusion}

This study exploits detailed knowledge of features of a community-level, infrastructure-based water and sanitation intervention to obtain quasi-experimental estimates of the program's causal effects. We find that the program reduced severe cases of diarrhea by approximately 30\% to 50\%.

These positive and large results differ from the null findings of two recent cluster-randomized trials evaluating sanitation-only interventions in rural India, one in Orissa (Clasen et al. 2014) and the other in Madhya Pradesh (Patil et al. 2014). We do not view our results as contradictory, for two reasons. First, RHEP is a package of a communal water tank, piped water to the home, and household latrines and bathing facilities. This evaluation therefore does not provide information on the effectiveness of the individual components, but the contrast with the RCT results suggests that this "full package" is important. Second, latrine use was relatively low in the two RCTs, which likely limited their health impact (Brown and Clasen 2012). We speculate that providing a tap for piped water at the toilet reduced barriers to maintenance and hygienic use, but further research is needed to understand the factors that motivate or impede use of sanitation facilities (Coffey et al. 2014, Gertler et al. 2015).

To what extent can this approach be generalized? As of March 2013, Gram Vikas water and sanitation programs reached 1,200 villages in Orissa, West Bengal and Andhra Pradesh, and started to expand in the Gambia and Tanzania (Gram Vikas 2013). As noted above, the cost per household is relatively low, especially the annual maintenance costs (about \$11). A complete costbenefit assessment would require monetizing all of the program's benefits, for which data are not available. These other benefits may include reductions in the incidence of other morbidities such as stunting or soil-transmitted helminth infections (Spears, Ghosh, and Cumming 2013, Strunz et al. 2014), decreases in time spent collecting water (Pattanayak et al. 2010, Kremer et al. 2011, Devoto et al. 2012), and the amenity value of private toilets.

However, there may be non-monetary limits to the approach. GV partners only with villages it believes capable of building the institutional capacity to complete the project with $100 \%$ participation and to sustain the facilities after construction is finished. These are important and perhaps unusual characteristics of a village, and they may limit external validity: a program technically similar to RHEP but targeted at villages lacking these characteristics may be less successful, because it would fail to capture complementarities and externalities. Gram Vikas is also a widely recognized NGO, and some of their ability to build consensus and convince villagers 
may not be easy to reproduce, though it is worth noting that their power to persuade did not extend to convincing people to use smokeless stoves (Hanna, Duflo, and Greenstone 2014).

Therefore this paper is best seen as a "proof of concept": an infrastructure-based approach can significantly reduce diarrhea and other morbidity rates in rural areas, if it is universal and includes both in-home water and sanitation facilities. There may be different ways to get there (low financial cost but high social capital like here, or higher financial investment), but this approach is rare in offering demonstrated effectiveness over the short and medium run. It seems unwise to write off rural infrastructure-based interventions, as has been the case in many policy conversations (Clasen and Haller 2008, WHO - UNICEF 2014).

\section{REFERENCES}

Arnold, Benjamin F, Clair Null, Stephen P Luby, Leanne Unicomb, Christine P Stewart, Kathryn G Dewey, Tahmeed Ahmed, et al. 2013. Cluster-randomised controlled trials of individual and combined water, sanitation, hygiene and nutritional interventions in rural Bangladesh and Kenya: the WASH Benefits study design and rationale. BMJ Open no. 3.

Barnard, Sharmani, Parimita Routray, Fiona Majorin, Rachel Peletz, Sophie Boisson, Antara Sinha, and Thomas Clasen. 2013. Impact of Indian Total Sanitation Campaign on Latrine Coverage and Use: A Cross-Sectional Study in Orissa Three Years following Programme Implementation. PLoS ONE no. 8 (8).

Berry, James M., Greg M. Fischer, and Raymond P. Guiteras. 2012. Eliciting and Utilizing Willingness to Pay: Evidence from Field Trials in Northern Ghana.

Bertrand, Marianne, Esther Duflo, and Sendhil Mullainathan. 2004. How Much Should We Trust Differences-in-Differences Estimates? The Quarterly Journal of Economics no. 119 (1):249-275.

Bill \& Melinda Gates Foundation. 2011. Gates Foundation Launches Effort to Reinvent the Toilet.

Brown, Joe, and Thomas Clasen. 2012. High Adherence Is Necessary to Realize Health Gains from Water Quality Interventions. PLoS ONE no. 7 (5).

Cairncross, Sandy, and Vivian Valdmanis. 2006. "Water Supply, Sanitation, and Hygiene Promotion." In Disease Control Priorities in Developing Countries, edited by Dean T. Jamison, Joel G. Breman, Anthony R. Measham, George Alleyne, Mariam Claeson, David B. Evans, Prabhat Jha, Anne Mills and Philip Musgrove. Washington (DC): World Bank.

Clasen, Thomas, Sophie Boisson, Parimita Routray, Belen Torondel, Melissa Bell, Oliver Cumming, Jeroen Ensink, et al. 2014. Effectiveness of a rural sanitation programme on diarrhoea, soil-transmitted helminth infection, and child malnutrition in Odisha, India: a cluster-randomised trial. The Lancet Global Health no. 2:e645-e653.

Clasen, Thomas F., and Laurence Haller. 2008. Water Quality Interventions to Prevent Diarrhoea: Cost and Cost-Effectiveness. World Health Organization. 
Clasen, Thomas, Wolf-Peter Schmidt, Tamer Rabie, Ian Roberts, and Sandy Cairncross. 2007. Interventions to improve water quality for preventing diarrhoea: systematic review and meta-analysis. BMJ no. 334 (7597):782.

Coffey, Diane, Aashish Gupta, Payal Hathi, Dean Spears, Nikhil Srivastav, and Sangita Vyas. 2014. Culture and the health transition: Understanding sanitation behavior in rural north India.

Cohen, Jessica, Pascaline Dupas, and Simone Schaner. 2014. Price Subsidies, Diagnostic Tests, and Targeting of Malaria Treatment Forthcoming, American Economic Review.

Curtis, Valerie, Sandy Cairncross, and Raymond Yonli. 2000. Review: Domestic hygiene and diarrhoea - pinpointing the problem. Tropical Medicine \& International Health no. 5:2232.

Cutler, David M., and Grant Miller. 2006. "Water, Water Everywhere: Municipal Finance and Water Supply in American Cities." In Corruption and Reform: Lessons from America's Economic History, edited by Edward L. Glaeser and Claudia Goldin, 153-184. Chicago, IL: University of Chicago Press.

Devoto, Florencia, Esther Duflo, Pascaline Dupas, William Parienté, and Vincent Pons. 2012. Happiness on Tap: Piped Water Adoption in Urban Morocco. American Economic Journal: Economic Policy no. 4 (4):68-99.

Eisenberg, Joseph N.S., James C. Scott, and Travis Porco. 2007. Integrating Disease Control Strategies: Balancing Water Sanitation and Hygiene Interventions to Reduce Diarrheal Disease Burden. American Journal of Public Health no. 97:846-852.

Eisenberg, Joseph N.S., James Trostle, Reed J.D. Sorensen, and Katherine F. Shields. 2012. Toward a Systems Approach to Enteric Pathogen Transmission: From Individual Independence to Community Interdependence. Annual Review of Public Health no. 33:239-257.

Fewtrell, Lorna, Rachel B. Kaufmann, David Kay, Wayne Enanoria, Laurence Haller, and John M. Colford Jr. 2005. Water, sanitation, and hygiene interventions to reduce diarrhoea in less developed countries: a systematic review and meta-analysis. The Lancet Infectious Diseases no. 5 (1):42-52.

Galiani, Sebastian, Paul Gertler, and Ernesto Schargrodsky. 2005. Water for Life: The Impact of the Privatization of Water Services on Child Mortality. Journal of Political Economy no. 113 (1):83-120.

Gates III, William H. 2012. Reflections on the Reinventing the Toilet Challenge.

Gertler, Paul, Manisha Shah, Maria Laura Alzua, Lisa Cameron, Sebastian Martinez, and Sumeet Patil. 2015. How Does Health Promotion Work? Evidence From The Dirty Business of Eliminating Open Defecation. NBER Working Paper no. 20997.

Geruso, Michael, and Dean Spears. 2015. Neighborhood Sanitation and Infant Mortality. National Bureau of Economic Research Working Paper Series no. No. 21184.

Government of India. 2012. Houses, Household Amenities and Assets: Latrine Facilities.

Gram Vikas. 2001. Rural Health and Environment Programme. Gram Vikas.

Gram Vikas. 2004. Rural Health and Environment Programme in Orissa. Gram Vikas.

Gram Vikas. 2005. Annual Report 2004-2005. Gram Vikas.

Gram Vikas. 2013. Annual Report 2012-2013. Gram Vikas.

Guiteras, Raymond, James Levinsohn, and Ahmed Mushfiq Mobarak. 2015. Encouraging sanitation investment in the developing world: A cluster-randomized trial. Science no. 348 (6237):903-906. 
Gupta, Aashish, Dean Spears, Diane Coffey, Nidhi Khurana, Nikhil Srivastav, Payal Hathi, and Sangita Vyas. 2014. Revealed Preference for Open Defecation. Economic and Political Weekly no. 49:43-55.

Hanna, Rema, Esther Duflo, and Michael Greenstone. 2014. Up in Smoke: The Influence of Household Behavior on the Long-Run Impact of Improved Cooking Stoves. Manuscript, Harvard University. Forthcoming, American Economic Journal: Economic Policy.

Jenkins, Marion W., and Val Curtis. 2005. Achieving the 'good life': Why some people want latrines in rural Benin. Social Science \& Medicine no. 61 (11):2446-2459.

Keirns, Pamela. 2007. Water supply and sanitation services for the rural poor: the Gram Vikas experience. Rugby, UK: Practical Action Publishing.

Keiser, Jennifer, Burton H. Singer, and Jürg Utzinger. 2005. Reducing the burden of malaria in different eco-epidemiological settings with environmental management: a systematic review. The Lancet Infectious Diseases no. 5 (11):695-708.

Kotloff, Karen L., James P. Nataro, William C. Blackwelder, Dilruba Nasrin, Tamer H. Farag, Sandra Panchalingam, Yukun Wu, et al. 2013. Burden and aetiology of diarrhoeal disease in infants and young children in developing countries (the Global Enteric Multicenter Study, GEMS): a prospective, case-control study. The Lancet no. 382 (9888):209-222.

Kremer, Michael, Jessica Leino, Edward Miguel, and Alix Peterson Zwane. 2011. Spring Cleaning: Rural Water Impacts, Valuation, and Property Rights Institutions. The Quarterly Journal of Economics no. 126 (1):145-205.

Ministry of Drinking Water and Sanitation. 2014. Restructuring of the Nirmal Bharat Abhiyan into Swachh Bharat Mission. Press Information Bureau, Government of India.

Ministry of Rural Development. 2014. Government to spend about 2 lakh Crore rupees for Swachh Bharat Mission More than 11 crore toilets will be built in 5 years. Press Information Bureau, Government of India.

Modi, Narendra. 2014. English rendering of Prime Minister Shri Narendra Modi's address at the launch of Swachh Bharat Mission at Rajpath. Press Information Bureau, Government of India.

Patil, Sumeet R., Benjamin F. Arnold, Alicia L. Salvatore, Bertha Briceno, Sandipan Ganguly, John M. Colford, Jr, and Paul J. Gertler. 2014. The Effect of India's Total Sanitation Campaign on Defecation Behaviors and Child Health in Rural Madhya Pradesh: A Cluster Randomized Controlled Trial. PLoS Med no. 11:e1001709.

Pattanayak, Subhrendu K., Christine Poulos, Jui-Chen Yang, and Sumeet Patil. 2010. How valuable are environmental health interventions? Evaluation of water and sanitation programmes in India. Bulletin of the World Health Organization no. 88 (7):535-542.

Perez, Eduardo, Jason Cardosi, Yolande Coombes, Jacqueline Devine, Amy Grossman, Craig Kullmann, C Ajith Kumar, et al. 2012. What Does It Take to Scale Up Rural Sanitation? In Water and Sanitation Program Working Paper: World Bank.

Prüss-Ustün, Annette, Jamie Bartram, Thomas Clasen, John M. Colford, Oliver Cumming, Valerie Curtis, Sophie Bonjour, et al. 2014. Burden of disease from inadequate water, sanitation and hygiene in low- and middle-income settings: a retrospective analysis of data from 145 countries. Tropical Medicine \& International Health no. 19 (8):894-905.

Prüss-Üstün, Annette, Robert Bos, Fiona Gore, and Jamie Bartram. 2008. Safer water, better health: costs, benefits and sustainability of interventions to protect and promote health. Geneva, Switzerland: World Health Organization. 
Pruss-Ustun, Annette, David Kay, Lorna Fewtrell, and Jamie Bartram. 2004. "Unsafe water, sanitation and hygiene." In Comparative Quantification of Health Risks: Global and Regional Burden of Disease Attributable to Selected Major Risk Factors, edited by Majid Ezzati, Alan D. Lopez, Anthony Rodgers and Christopher JL Murray. World Health Organization.

Schmidt, Wolf-Peter, Benjamin F Arnold, Sophie Boisson, Bernd Genser, Stephen P Luby, Mauricio L Barreto, Thomas Clasen, et al. 2011. Epidemiological methods in diarrhoea studies — an update. International Journal of Epidemiology no. 40 (6):1678-1692.

Schmidt, Wolf-Peter, Sandy Cairncross, Mauricio L Barreto, Thomas Clasen, and Bernd Genser. 2009. Recent diarrhoeal illness and risk of lower respiratory infections in children under the age of 5 years. International Journal of Epidemiology no. 38 (3):766-772.

Spears, Dean. 2012. Effects of Rural Sanitation on Infant Mortality and Human Capital: Evidence from a Local Governance Incentive in India. In Princeton University Research Program in Development Studies.

Spears, Dean, Arabinda Ghosh, and Oliver Cumming. 2013. Open Defecation and Childhood Stunting in India: An Ecological Analysis of New Data from 112 Districts. PLoS ONE no. 8 (9):e73784.

Strunz, Eric C, David G Addiss, Meredith E Stocks, Stephanie Ogden, Jürg Utzinger, and Matthew C Freeman. 2014. Water, sanitation, hygiene, and soil-transmitted helminth infection: a systematic review and meta-analysis. PLoS medicine no. 11 (3):e1001620.

Times of India. 2013. Build toilets first and temples later Narenda Modi says. Times of India.

VanDerslice, James, and John Briscoe. 1995. Environmental Interventions in Developing Countries: Interactions and Their Implications. American Journal of Epidemiology no. 141:135-144.

Waddington, Hugh, and Birte Snilstveit. 2009. Effectiveness and sustainability of water, sanitation, and hygiene interventions in combating diarrhoea. Journal of Development Effectiveness no. 1 (3):295-335.

Wagner, Edmund G., and J.N. Lanoix. 1958. Excreta Disposal for Rural Areas and Small Communities, WHO Monograph Series. Geneva, Switzerland: World Health Organization.

Walker, Christa L Fischer, and Robert E Black. 2009. Commentary: What is the role of comorbidity in child mortality? International Journal of Epidemiology no. 38 (3):772-774.

White, Gilbert F., David J. Bradley, and Anne U. White. 1972. Drawers of water: University of Chicago Press.

WHO - UNICEF. 2014. Progress on sanitation and drinking-water - 2014 update. Geneva: World Health Organization and UNICEF Joint Monitoring Programme on Water and Sanitation.

Wolf, Jennyfer, Annette Prüss-Ustün, Oliver Cumming, Jamie Bartram, Sophie Bonjour, Sandy Cairncross, Thomas Clasen, et al. 2014. Systematic review: Assessing the impact of drinking water and sanitation on diarrhoeal disease in low- and middle-income settings: systematic review and meta-regression. Tropical Medicine \& International Health no. 19 (8):928-942.

World Health Organization. 2013. Diarrhoeal disease.

Zwane, Alix Peterson, and Michael Kremer. 2007. What Works in Fighting Diarrheal Diseases in Developing Countries? A Critical Review. World Bank Research Observer no. 22:1-24. 


\section{Tables}

Table 1: Descriptive Statistics

\begin{tabular}{|c|c|c|c|}
\hline & $\begin{array}{c}\text { Sample A } \\
(1)\end{array}$ & $\begin{array}{c}\text { Sample B } \\
(2)\end{array}$ & $\begin{array}{c}\text { Sample C } \\
(3)\end{array}$ \\
\hline \multicolumn{4}{|l|}{ Village characteristics: } \\
\hline Number of villages & 96 & 75 & 73 \\
\hline Number of households per village & $\begin{array}{c}88.4 \\
(60.0)\end{array}$ & $\begin{array}{c}91.6 \\
(61.4)\end{array}$ & $\begin{array}{l}102.2 \\
(70.4)\end{array}$ \\
\hline Village population & $\begin{array}{c}493.3 \\
(327.2)\end{array}$ & $\begin{array}{c}509.0 \\
(324.2)\end{array}$ & $\begin{array}{c}527.0 \\
(327.6)\end{array}$ \\
\hline \multicolumn{4}{|l|}{ Observation counts: } \\
\hline Num. of months betw. first obs. and initiation of service & $\begin{array}{l}16.4 \\
(9.7)\end{array}$ & $\begin{array}{l}17.6 \\
(5.4)\end{array}$ & $\begin{array}{l}11.5 \\
(1.2)\end{array}$ \\
\hline Num. of obs. before initiation of service & $\begin{array}{l}17.4 \\
(8.3)\end{array}$ & $\begin{array}{l}17.0 \\
(5.3)\end{array}$ & $\begin{array}{l}11.3 \\
(1.3)\end{array}$ \\
\hline Num. of months betw. initiation of service and last obs. & $\begin{array}{c}48.3 \\
(33.2)\end{array}$ & $\begin{array}{c}42.7 \\
(16.8)\end{array}$ & $\begin{array}{l}11.9 \\
(0.7)\end{array}$ \\
\hline Num. of obs. after initiation of service & $\begin{array}{c}45.4 \\
(31.5)\end{array}$ & $\begin{array}{c}41.2 \\
(16.5)\end{array}$ & $\begin{array}{l}11.8 \\
(0.8)\end{array}$ \\
\hline \multicolumn{4}{|l|}{ Health outcomes (per village-month observation): } \\
\hline Number of cases of diarrhea & $\begin{array}{c}0.64 \\
(1.44)\end{array}$ & $\begin{array}{c}0.68 \\
(1.45)\end{array}$ & $\begin{array}{c}0.87 \\
(1.59)\end{array}$ \\
\hline Number of cases of malaria & $\begin{array}{c}0.96 \\
(2.11)\end{array}$ & $\begin{array}{c}0.99 \\
(2.12)\end{array}$ & $\begin{array}{c}0.90 \\
(1.94)\end{array}$ \\
\hline Number of cases of fever & $\begin{array}{c}2.70 \\
(3.68)\end{array}$ & $\begin{array}{c}2.66 \\
(3.76)\end{array}$ & $\begin{array}{c}2.58 \\
(3.69)\end{array}$ \\
\hline
\end{tabular}

Note: This table presents summary statistics on the number of villages and their characteristics, observation counts and timing, and health outcomes. The sample used varies by column. Column (1) ("Sample A") includes all observations from villages for which the month of water activation is known. Column (2) ("Sample B") uses only observations from up to 24 months before to up to 59 months after the water supply is activated, and only villages which have at least 6 observations before and after. Column (3) ("Sample C") uses only observations in a one-year window around the activation of the water supply (12 months before through 11 months after), and restricts the sample to villages with at least 6 observations within this window on both sides. Standard deviations in parentheses. 
Table 2: The Effect of Water Improvement on Diarrhea

\begin{tabular}{lccc}
\hline & $\begin{array}{c}\text { Sample A } \\
(1)\end{array}$ & $\begin{array}{c}\text { Sample B } \\
(2)\end{array}$ & $\begin{array}{c}\text { Sample C } \\
(3)\end{array}$ \\
\hline Panel A: Mean shift & & & \\
Post-intervention & $-0.585^{* * *}$ & $-0.587^{* * *}$ & $-0.433^{* *}$ \\
& $(0.125)$ & $(0.138)$ & $(0.174)$ \\
Num. observations & 5,408 & 4,077 & 1,605 \\
Num. villages & 95 & 74 & 71 \\
Mean outcome pre-treatment & 1.076 & 1.091 & 1.180 \\
Panel B: Mean shift with village-specific trend & \\
Post-intervention & $-0.571^{* * *}$ & $-0.550^{* * *}$ & $-0.407^{* *}$ \\
& $(0.129)$ & $(0.158)$ & $(0.183)$ \\
Num. observations & 5,408 & 4,077 & 1,605 \\
Num. villages & 95 & 74 & 71 \\
Mean outcome pre-treatment & 1.076 & 1.091 & 1.180 \\
\hline
\end{tabular}

Note: Panel (A) presents estimates of Equation (2) in the text. Panel (B) additionally controls for villagespecific linear trends. The dependent variable is the number of cases of diarrhea reported as treated in a month. "Post-intervention" denotes the average effect of the intervention, corresponding to $\alpha$ in Equation (2). Each observation is one village-month-year. Estimation is by GLS regression. Each observation from village $v$ is weighted by $1 / N_{v}$, where $N_{v}$ is the total number of observations of village $v$. The sample used varies by column. Column (1) includes all observations from villages for which the month of water activation is known (Sample A in the text). Column (2) uses only observations from up to 24 months before to up to 59 months after the water supply is activated, and only villages which have at least 6 observations before and after (Sample B in the text). Column (3) only uses observations in a one-year window around the activation of the water supply (12 months before through 11 months after), and restricts the sample to villages with at least 6 observations within this window on both sides (Sample $\mathrm{C}$ in the text). All regressions include village and month-by-year fixed effects. Standard errors clustered by village are reported in parentheses. $* \mathrm{p}<0.10,{ }^{* *} \mathrm{p}<0.05, * * * \mathrm{p}<0.01$. 
Table 3: Effect of Program by Post-Intervention Period

\begin{tabular}{lcc}
\hline & $\begin{array}{c}\text { Sample A } \\
(1)\end{array}$ & $\begin{array}{c}\text { Sample B } \\
(2)\end{array}$ \\
\hline Months 0-35 & $-0.552^{* * *}$ & $-0.539^{* * *}$ \\
& $(0.133)$ & $(0.147)$ \\
Months 36+ & $-0.423^{* *}$ & $-0.406^{*}$ \\
& $(0.211)$ & $(0.229)$ \\
Num. observations & 5,408 & 4,077 \\
Num. villages & 95 & 74 \\
Mean outcome pre-treatment & 1.076 & 1.091 \\
p-value: coeffs. are equal & 0.293 & 0.316 \\
\hline
\end{tabular}

Notes: This table reports estimates of a variant of Equation (2), in which we estimate the effect separately for months 0-35 and beyond month 36. The dependent variable is the number of cases of diarrhea reported as treated in a month. "Months 0-35" denotes the average effect over months 0-35, and "Months 36+" denotes the average effect beyond month 36. Each observation is one village-month-year. Estimation is by GLS regression. Each observation from village $v$ is weighted by $1 / N_{v}$, where $N_{v}$ is the total number of observations of village $v$. The sample used varies by column. Column (1) includes all observations from villages for which the month of water activation is known (Sample A in the text). Column (2) uses only observations from up to 24 months before to up to 59 months after the water supply is activated, and only villages which have at least 6 observations before and after (Sample B in the text). All regressions include village and month-by-year fixed effects. Standard errors clustered by village are reported in parentheses. ${ }^{*} \mathrm{p}<0.10,{ }^{* *} \mathrm{p}<0.05,{ }^{* * *} \mathrm{p}<0.01$. 
Table 4: The Effect of Water Improvement on Malaria and Fever

\begin{tabular}{|c|c|c|c|c|c|c|}
\hline \multirow[t]{2}{*}{ Outcome variable: } & \multicolumn{3}{|c|}{ Malaria } & \multicolumn{3}{|c|}{ Fever } \\
\hline & $\begin{array}{l}\text { Sample A } \\
\text { (1) }\end{array}$ & $\begin{array}{c}\text { Sample B } \\
(2)\end{array}$ & $\begin{array}{c}\text { Sample C } \\
(3)\end{array}$ & $\begin{array}{c}\text { Sample A } \\
\text { (4) }\end{array}$ & $\begin{array}{c}\text { Sample B } \\
(5)\end{array}$ & $\begin{array}{c}\text { Sample C } \\
(6)\end{array}$ \\
\hline \multicolumn{7}{|l|}{ Panel A: Mean shift } \\
\hline Post-intervention & $\begin{array}{c}-0.468^{* *} \\
(0.189)\end{array}$ & $\begin{array}{c}-0.528^{* *} \\
(0.238)\end{array}$ & $\begin{array}{l}-0.494^{*} \\
(0.275)\end{array}$ & $\begin{array}{c}-0.392 \\
(0.303)\end{array}$ & $\begin{array}{l}-0.622^{*} \\
(0.347)\end{array}$ & $\begin{array}{l}-0.329 \\
(0.414)\end{array}$ \\
\hline Num. observations & 4,572 & 3,360 & 1,133 & 4,571 & 3,359 & 1,133 \\
\hline Num. villages & 94 & 75 & 55 & 94 & 75 & 55 \\
\hline Mean outcome pre-treatment & 1.328 & 1.280 & 1.150 & 3.159 & 2.888 & 2.748 \\
\hline \multicolumn{7}{|c|}{ Panel B: Mean shift with village-specific trend } \\
\hline Post-intervention & $\begin{array}{c}-0.465^{* *} \\
(0.213)\end{array}$ & $\begin{array}{l}-0.290 \\
(0.231)\end{array}$ & $\begin{array}{l}-0.527^{*} \\
(0.304)\end{array}$ & $\begin{array}{l}-0.269 \\
(0.353)\end{array}$ & $\begin{array}{l}-0.472 \\
(0.400)\end{array}$ & $\begin{array}{c}-0.332 \\
(0.396)\end{array}$ \\
\hline Num. observations & 4,572 & 3,360 & 1,133 & 4,571 & 3,359 & 1,133 \\
\hline Num. villages & 94 & 75 & 55 & 94 & 75 & 55 \\
\hline Mean outcome pre-treatment & 1.328 & 1.280 & 1.150 & 3.159 & 2.888 & 2.748 \\
\hline
\end{tabular}

Note: Panel (A) presents estimates of Equation (2) in the text. Panel (B) additionally controls for villagespecific linear trends. In columns (1) - (3), the dependent variable is the number of cases of malaria treated in a month; in columns (4) - (6), the dependent variable is the number of cases of fever treated in a month; "Post-intervention" denotes the average effect of the intervention, corresponding to $\alpha$ in Equation (2). Each observation is one village-month-year. Estimation is by GLS regression. Each observation from village $v$ is weighted by $1 / N_{v}$, where $N_{v}$ is the total number of observations of village $v$. The sample used varies by column. Columns (1) and (4) ("Sample A") include all observations from villages for which the month of water activation is known. Columns (2) and (5) ("Sample B") use only observations from up to 24 months before to up to 59 months after the water supply is activated, and only villages which have at least 6 observations before and after. Columns (3) and (6) ("Sample C") use only observations in a one-year window around the activation of the water supply (12 months before through 11 months after), and restricts the sample to villages with at least 6 observations within this window on both sides. Standard errors clustered by village are reported in parentheses. $* \mathrm{p}<0.10,{ }^{* *} \mathrm{p}<0.05, * * * \mathrm{p}<0.01$. 


\section{Figures}

Figure 1: Evolution of latrine use and water provision

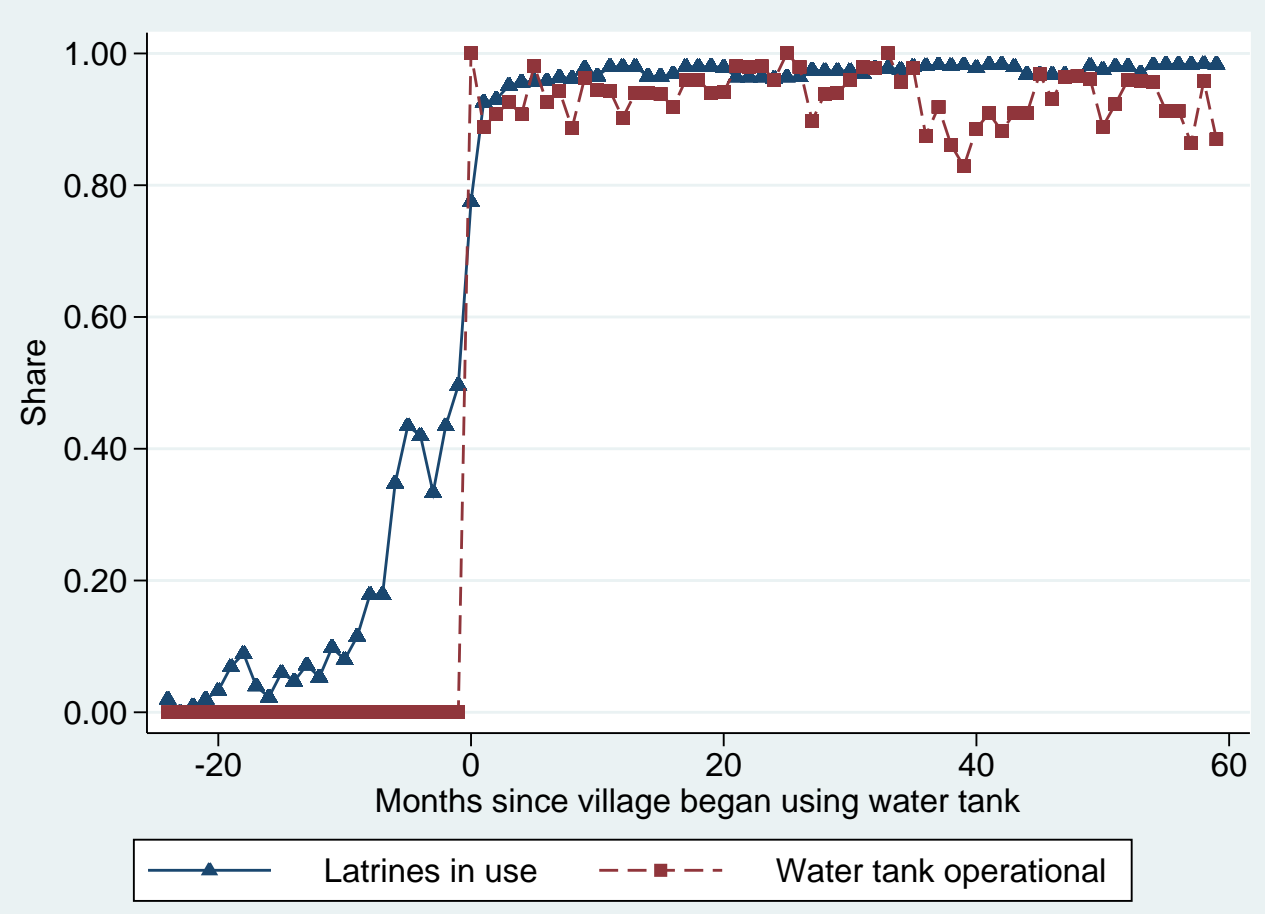

Notes: this figure shows the evolution of village-level latrine coverage around the time at which water services are activated. The $\mathrm{x}$-axis represents time in months, relative to the month in which the village's water tank is activated. The water tank is activated in month $\tau=0$. The series "Latrines in use" plots the median village-level share of households that own and use a latrine. Pre-intervention mean: 0.189; post-intervention mean: 0.966. The series "Water tank operational" plots the share of villages with their water tank fully operational. Pre-intervention mean: 0; post-intervention mean: 0.939. The sample consists of villages in "Sample B", as defined in the text, with the additional restriction that there be at least 6 observations of both latrine ownership and use and the operational status of the water tank both before and after the activation of services in the window $-24 \leq \tau \leq 59$. This sample consists of 54 villages. 
Figure 2: Event Analysis Within Twelve Months of Beginning Water Improvement Impact on Cases of Diarrhea Treated Per Month

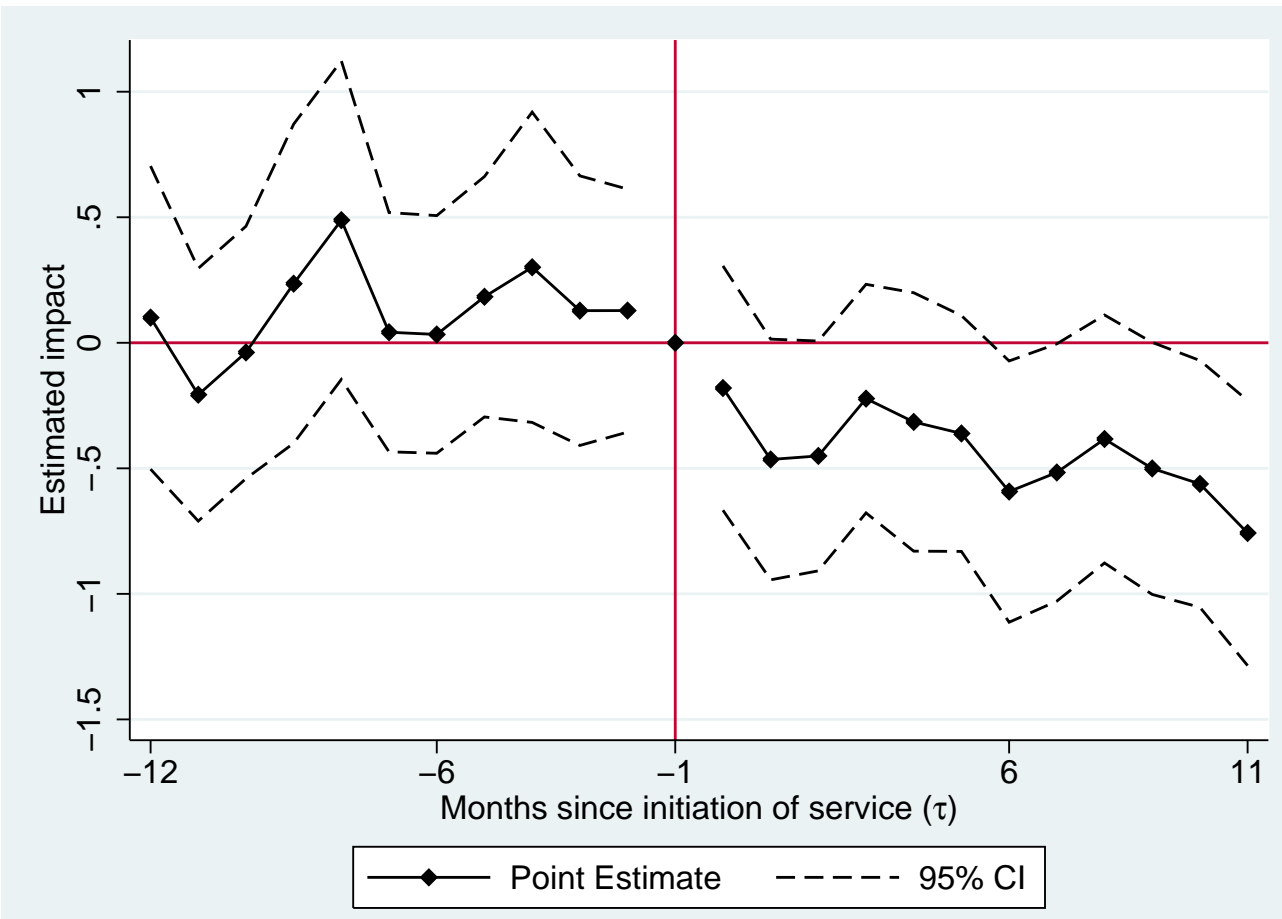

Notes: this figure describes the month-by-month estimated impact of the intervention by plotting parameter estimates for each value of $\tau$ in Equation (1) in the text. The dependent variable is the number of cases of diarrhea treated in a given month. $\tau$ represents the month relative to initiation of service, with $\tau_{0}$ the month in which service began. All estimates are relative to the month prior to the initiation of service, so the estimate on $\tau_{-1}$ is normalized to zero. The regression includes village fixed effects and month-by-year fixed effects. Each observation is one village-month-year. Estimation is by GLS regression. Each observation from village $v$ is weighted by $1 / N_{v}$, where $N_{v}$ is the total number of observations of village $v$. The dashed lines represent $95 \%$ confidence intervals for the individual estimates. The sample is "Sample B": only observations from up to 24 months before to up to 59 months after the water supply is activated, and only villages with at least 6 observations before and 6 observations after the activation of services. Standard errors are clustered at the village level. 
Figure 3: Event Analysis from Two Years Before to Five Years After Water Improvement Impact on Cases of Diarrhea Treated Per Month

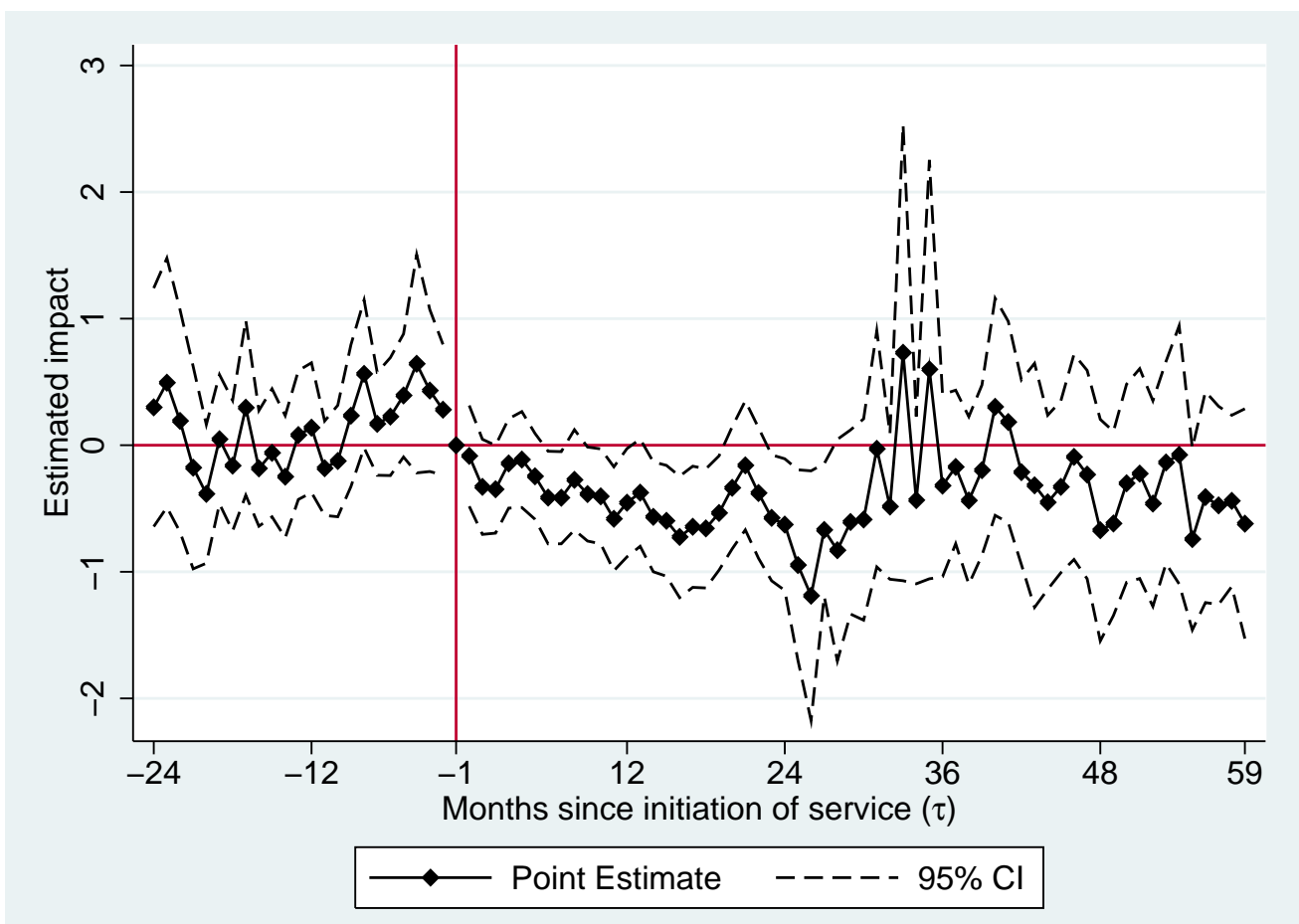

Notes: this figure describes the month-by-month estimated impact of the intervention by plotting parameter estimates for each value of $\tau$ in Equation (1) in the text. The dependent variable is the number of cases of diarrhea treated in a given month. $\tau$ represents the month relative to initiation of service, with $\tau_{0}$ the month in which service began. All estimates are relative to the month prior to the initiation of service, so the estimate on $\tau_{-1}$ is normalized to zero. The regression includes village fixed effects and month-by-year fixed effects. Each observation is one village-month-year. Estimation is by GLS regression. Each observation from village $v$ is weighted by $1 / N_{v}$, where $N_{v}$ is the total number of observations of village $v$. The dashed lines represent $95 \%$ confidence intervals for the individual estimates. The sample is "Sample B": only observations from up to 24 months before to up to 59 months after the water supply is activated, and only villages with at least 6 observations before and 6 observations after the activation of services. Standard errors are clustered at the village level. 


\section{Figure 4: Estimated Impact on Cases of Diarrhea Robustness Checks}

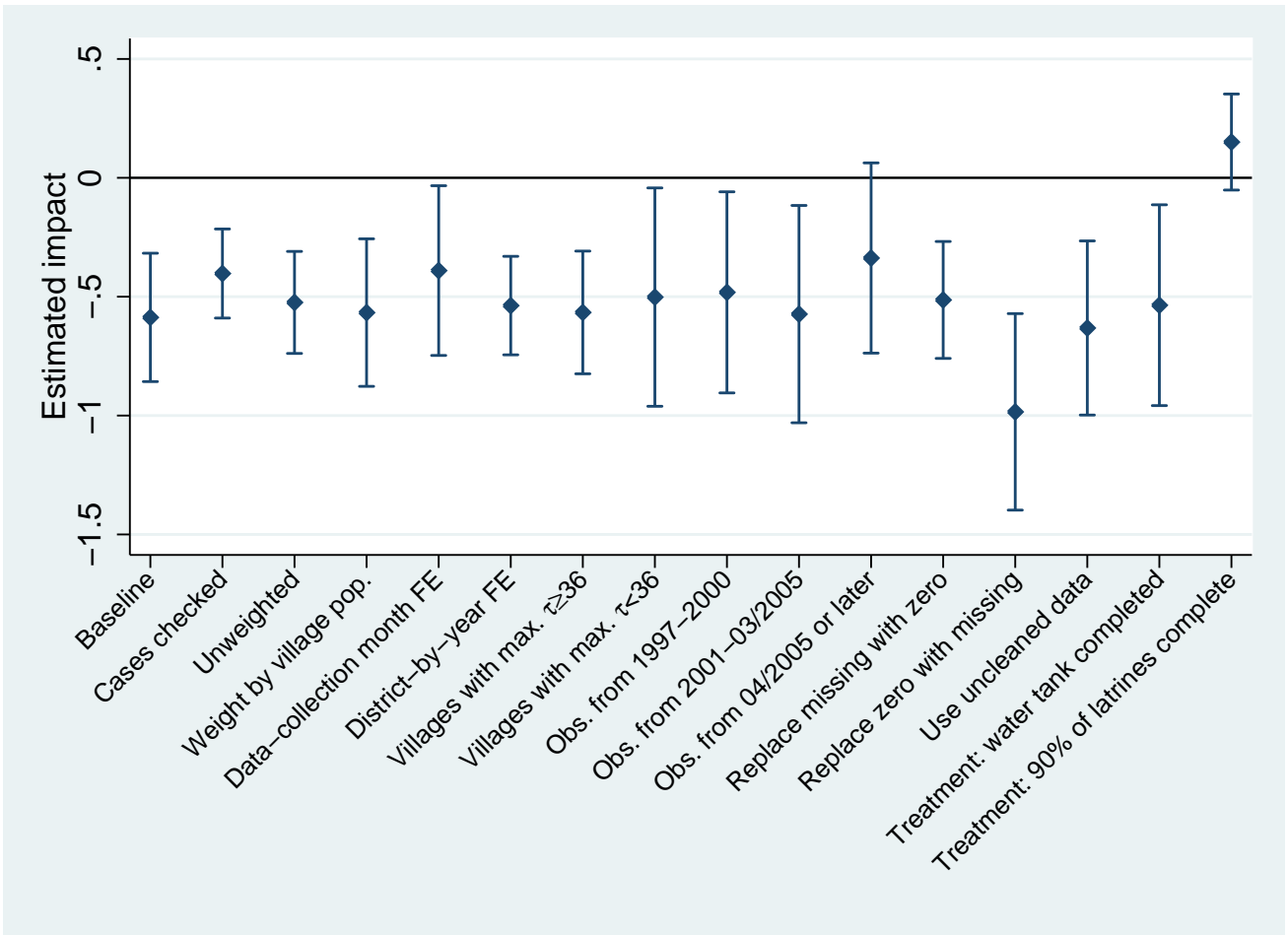

Notes: this figure reports estimated treatment effects, with $95 \%$ confidence intervals, for each of a series of variants on Equation (2) in the main text. The variant for each specification is described briefly by the label on the $\mathrm{x}$ axis, and in greater detail in the text of the Supporting Information. In all cases, the sample corresponds to Sample B in the main text, consisting of observations from two years before to five years after the initiation of services $(-24 \leq \tau \leq 59)$, and including only villages with at least six observations before and six observations after the initiation of services. All regressions include village and month-by-year fixed effects. Standard errors are clustered at the village level. 


\title{
Short and Medium Run Health Impacts of Addressing Complementarities and Externalities in Water and Sanitation Online Appendix
}

\author{
Esther Duflo* Michael Greenstone ${ }^{\dagger} \quad$ Raymond Guiteras ${ }^{\ddagger \S}$ \\ Thomas Clasen
}

August 2015

This document contains supplementary materials for the paper "The Short- and MediumRun Impacts of In-Home Water Supply and Sanitation on Diarrhea in Rural India." It is organized as follows: Section A1 provides detail on the robustness checks; Section A2 discusses results for malaria and fever; Section A3 describes the data-cleaning process in detail; Section A4 provides an approximate calculation of program costs.

*Department of Economics, Massachusetts Institute of Technology, Cambridge MA 02142, USA and National Bureau of Economic Research, Cambridge MA 02138, USA.

${ }^{\dagger}$ University of Chicago, Department of Economics, Chicago IL 60637, USA and National Bureau of Economic Research, Cambridge MA 02138, USA.

${ }^{\ddagger}$ Department of Economics, University of Maryland, College Park MD 20742 USA.

§To whom correspondence should be addressed. Email: guiteras@econ.umd.edu

IDepartment of Environmental Health, Rollins School of Public Health, Emory University, Atlanta, GA USA and Faculty of Infectious and Tropical Diseases, London School of Hygiene and Tropical Medicine, London WC1E 7H, UK. 


\section{A1 Robustness Checks}

In this section, we provide further detail on the series of robustness checks provided in Figure 3 of the main text. Each is describe a series of robustness checks estimating variants on Equation (2). We re-estimate Equation (2) in the following ways:

1. "Baseline": replicates Table 2, Panel A, Column (2) for comparison;

2. "Cases checked": use the number of cases checked (rather than treated) in a month as the dependent variable;

3. "Unweighted": no weighting. That is, each observation receives equal weight, so each village effectively is weighted by the number of observations;

4. "Weight by village population": weight each village by its mean population;

5. "Data-collection month fixed effects": include fixed effects for the number of months since data collection began;

6. "District-by-year fixed effects": include fixed effects for each district-year (19 districts, 11 years, although not all districts are in the dataset in all years);

7. "Villages with max. $\tau \geq 36$ ": include only villages with 3 years of post-intervention data or more;

8. "Villages with max. $\tau<36$ ": include only villages less than 3 years of post-intervention data;

9. "Obs. from 1997-2000": include only data from the "early" phase of the program, 1997-2000;

10. "Obs. from 2001-03/2005": include only observations from 2001 through March 2005. Two potentially important differences exist between the data up to and including fiscal year 2004/05 (ending in March 2005) and thereafter (see "Obs. in 04/2005 or later" below). First, Gram Vikas consistently entered hard-copy forms into a database beginning in April 2005, so most of the subsequent data come from this database, rather than the data we created from scanning old paper forms. Second, our first discussions with Gram Vikas about an evaluation took place in July 2005. This could have introduced bias into data collection, although methods did not change and the field and implementation staff were unaware of the evaluation; 
11. "Obs. from 04/2005 or later": include only observations from April 2005 or later. See above discussion under "Obs. from 2001-03/2005" above;

12. "Replace missing with zero": if the outcome variable is missing in a village-month observation, code it as zero.

13. "Replace zero with missing": if the outcome variable is recorded as zero in a villagemonth observation, code it as missing;

14. "Use uncleaned data": use raw data as entered, without data cleaning;

15. "Treatment: water tank completed": define the intervention as having started when construction of the village's water tank is complete;

16. "Treatment: $90 \%$ of latrines complete": define the intervention as having started when $90 \%$ of households in a village have completed their latrine.

\section{A2 Results for Malaria and Fever}

Figures A1 and A2 present the results of the same series of robustness checks as those conducted for cases of diarrhea (described in Section A1, with results reported in Figure 3 of the main text). Data on cases of malaria and fever were not systematically collected during the period 1997-2000, so the "Obs. from 1997-2000" specification is dropped. For both malaria and fever, 5 of 15 specifications are statistically significant at the $95 \%$ level, as compared to 14 of 16 for diarrhea.

\section{A3 Data Cleaning}

This appendix describes preparation of the data for analysis. The original data were collected in three separate formats - one format for 1997-1999, one for 2000-2001, and another for 2002-2005 - where each format presented a slightly different set of variables. The original handwritten survey data were scanned and transmitted to a data firm in India, which entered them into electronic records using double-entry for accuracy. The original records called for English entries, but data were sometimes recorded in Oriya (the predominant language in Orissa). Our data entry company assigned Oriya-literate employees to our project. Gram Vikas also converted paper records to electronic format starting in 2002. Comparison of the 2002-2005 data entered by GV to that entered by the data firm indicates that the data firm's version had fewer errors, so for 2002-2005 we mainly use the Indian firm's version of 
the data, though we fill in some gaps (mainly from paper records that were lost) with the GV-entered data. Because we only scanned the paper records through 2005, all 2006 and 2007 data come from GV's data-entry. Although all forms reported deaths, the total number of reported deaths was extremely small and hence not used in analysis.

The most relevant differences between the survey forms are diarrhea variables included in 1997-1999 and excluded from other forms, and other variables which appear in all forms except those used in 1997-99. The 1997-1999 form does not report on any illnesses other than diarrhea, but it does report the number of cases of diarrhea for children, the number of days that children suffer diarrhea, and the number of working days lost to diarrhea. Other forms do not report these more detailed diarrhea measures. Also, the 1997-1999 data do not report school attendance, the number of households, number of individuals, or the number of children.

Basic data cleaning steps included the following:

- correction of village names and code numbers;

- correction of incorrectly entered dates;

- conversion of numbers entered as strings;

- while most villages have continuous panels - every consecutive month is observed some observations were distant temporal outliers and appeared a year or more after all other observations from the same village. Those outliers generally have values differing substantially from the other values in the village, so we exclude them from the analysis.

By comparing against images of the original handwritten monthly survey documents we conclude that most of these anomalies came from the original paper data forms recorded by the supervisor, rather than from data-entry errors.

The data offer several potential indicators of the initiation of service:

- each month, the surveyor indicated whether the village water tank had begun operation;

- each month, the surveyor indicated whether construction of the village water tank had been completed;

- each month, the surveyor recorded the number of latrines the village had built.

The paper focuses on the first, since it is the operation of the water tank, rather the construction of infrastructure, that should affect environmental conditions and health. In the 
robustness checks described in Section A1, we provide estimates using alternative indicators for the initiation of service.

The main estimates also reflect cleaning of the underlying data for all variables. Much of the cleaning uses redundant information in the village-level data. For example, population levels in a village are smooth, so comparing adjacent time periods clarifies when outlier population values are typos. Specifically, the following general rules for cleaning the data represent some of the more important:

- for all variables, extreme outlier values which can be identified as obvious typos are corrected, while outliers which cannot be assigned a certain correct value are coded to be missing;

- water tank variables (tank construction, usage, latrine construction) nondecreasing by default. That is, once a village's water tank is reported as functional, it is coded as functional in all future periods unless it is specifically reported to be non-functional (e.g. if there is a maintenance problem). This is because MPRs often skipped the section on water tank construction if the tank had already been in use for many months. As discussed in the main text, treatment is defined as the period after initiation of services, so a village is coded as "treated" in all months after the first month in which the water tank is operational, whether or not the tank is working in that particular month;

- population values (households, adults, children) which have the value zero are recoded to missing. The total village population must roughly equal the number of children plus the number of adults.

\section{A4 Program Costs}

Table A1 presents a calculation of approximate costs per household in a typical village of 50 households, based on Gram Vikas (2004) and Gram Vikas (2005). Costs calculated for a village of 50 households, and Indian rupees are converted to US dollars at the average 19972006 market exchange rate of $45 \mathrm{INR} /$ USD. The cost components are construction of toilets and bath houses, construction of water supply and project development costs (primarily GV staff time spent in organizing and capacity-building), distinguishing between villagers' contributions and inputs purchased with external funds. The value of villagers' labor is assessed at US $\$ 1$ per day, the local agricultural day labor wage. This may be an overstatement since most work takes place outside the planting and harvest seasons, i.e. in times in which the 
opportunity cost of villagers' time is lower. The approximate construction cost per household is $\$ 440$ with annual maintenance costs of roughly $\$ 11$. Assuming an interest rate of $10 \%$ per year and given the intended useful 20-year life of the tank and sanitary facilities, the equivalent annuity cost is approximately $\$ 58$ per household per year. Average 2007-2008 annual household consumption in rural Orissa is reported in National Sample Survey Organisation (2010) as $\$ 738$, converted to US dollars at the 2007-2008 exchange rate of 40 INR/USD. 


\section{References}

Valerie Curtis, Sandy Cairncross, and Raymond Yonli. Review: Domestic hygiene and diarrhoea - pinpointing the problem. Tropical Medicine 83 International Health, 5(1):2232, January 2000. ISSN 1365-3156. doi: 10.1046/j.1365-3156.2000.00512.x. URL http: //onlinelibrary.wiley.com/doi/10.1046/j.1365-3156.2000.00512.x/abstract.

Gram Vikas. Rural health and environment programme in Orissa, 2004.

Gram Vikas. Annual report 2004-2005, 2005.

National Sample Survey Organisation. Household consumer expendiature in India, 2007-08. Report 530, Ministry of Statistics and Programme Implementation, Government of India, March 2010. 


\section{Tables}

Table A1: Approximate Costs per Household (US\$)

\begin{tabular}{lrrr}
\hline & Household & External & Total \\
\hline Construction costs: & & & \\
Toilet and bath house & 66.7 & 77.8 & 144.4 \\
Water supply & 72.2 & 105.6 & 177.8 \\
Project development & 138.9 & 116.7 & 116.7 \\
Total & & & 438.9 \\
Maintenance (annual) & & 11.1 \\
Assumed Interest Rate & & $10 \%$ \\
Assumed Useful Life (years) & & 20 \\
Net Present Value of Costs & & 542.8 \\
Equivalent 20-year Annuity & & 57.8 \\
Annual household consumption & & 737.9 \\
\hline
\end{tabular}

Notes: Information from Gram Vikas (2004) and Gram Vikas (2005). Costs calculated for a village of 50 households. Figures in Indian rupees converted to US dollars at the mean 1997-2006 market exchange rate of $45 \mathrm{INR} / \mathrm{USD}$. Project development costs are primarily wages paid to Gram Vikas staff during startup and data collection. Average 2007-2008 annual household consumption in rural Orissa from National Sample Survey Organisation (2010), converted to US dollars at the 2007-2008 average exchange rate of 40 INR/USD. 
Table A2: Placebo Check: Effect on Tuberculosis

\begin{tabular}{lccc}
\hline & $\begin{array}{c}\text { Sample A } \\
(1)\end{array}$ & $\begin{array}{c}\text { Sample B } \\
(2)\end{array}$ & $\begin{array}{c}\text { Sample C } \\
(3)\end{array}$ \\
\hline Panel A: Mean shift & & & \\
Post-intervention & -0.052 & -0.012 & -0.087 \\
& $(0.056)$ & $(0.063)$ & $(0.071)$ \\
Num. observations & 2,960 & 2,315 & 836 \\
Num. villages & 88 & 74 & 51 \\
Mean outcome pre-treatment & 0.145 & 0.096 & 0.056 \\
Panel B: Mean shift with village-specific trend & \\
Post-intervention & 0.087 & 0.115 & -0.081 \\
& $(0.069)$ & $(0.081)$ & $(0.080)$ \\
Num. observations & 2,960 & 2,315 & 836 \\
Num. villages & 88 & 74 & 51 \\
Mean outcome pre-treatment & 0.145 & 0.096 & 0.056 \\
\hline
\end{tabular}

Note: Panel (A) presents estimates of Equation (2) in the text. Panel (B) additionally controls for village-specific linear trends. The dependent variable is the number of cases of tuberculosis reported in a month. "Post-intervention" denotes the average effect of the intervention, corresponding to $\alpha$ in Equation (2). Each observation is one village-month-year. Estimation is by GLS regression. Each observation from village $v$ is weighted by $1 / N_{v}$, where $N_{v}$ is the total number of observations of village $v$. The sample used varies by column. Column (1) includes all observations from villages for which the month of water activation is known (Sample A in the text). Column (2) uses only observations from up to 24 months before to up to 59 months after the water supply is activated, and only villages which have at least 6 observations before and after (Sample B in the text). Column (3) only uses observations in a one-year window around the activation of the water supply (12 months before through 11 months after), and restricts the sample to villages with at least 6 observations within this window on both sides (Sample $\mathrm{C}$ in the text). All regressions include village and month-by-year fixed effects. Standard errors clustered by village are reported in parentheses. $* \mathrm{p}<0.10,{ }^{* *} \mathrm{p}<0.05,{ }^{* * *} \mathrm{p}<0.01$. 
Table A3: Placebo Check: Effect on Tuberculosis by Post-Intervention Period

\begin{tabular}{lcc}
\hline & $\begin{array}{c}\text { Sample A } \\
(1)\end{array}$ & $\begin{array}{c}\text { Sample B } \\
(2)\end{array}$ \\
\hline Months 0-35 & -0.021 & 0.025 \\
& $(0.057)$ & $(0.075)$ \\
Months 36+ & 0.093 & 0.130 \\
& $(0.087)$ & $(0.118)$ \\
Num. observations & 2,960 & 2,315 \\
Num. villages & 88 & 74 \\
Mean outcome pre-treatment & 0.145 & 0.096 \\
p-value: coeffs. are equal & 0.046 & 0.049 \\
\hline
\end{tabular}

Notes: This table reports estimates of a variant of Equation (2), in which we estimate the effect separately for months 0-35 and beyond month 36. The dependent variable is the number of cases of tuberculosis in a month. "Months 0-35" denotes the average effect over months 0-35, and "Months 36+" denotes the average effect beyond month 36. Each observation is one village-month-year. Estimation is by GLS regression. Each observation from village $v$ is weighted by $1 / N_{v}$, where $N_{v}$ is the total number of observations of village $v$. The sample used varies by column. Column (1) includes all observations from villages for which the month of water activation is known (Sample A in the text). Column (2) uses only observations from up to 24 months before to up to 59 months after the water supply is activated, and only villages which have at least 6 observations before and after (Sample B in the text). All regressions include village and month-by-year fixed effects. Standard errors clustered by village are reported in parentheses. ${ }^{*} \mathrm{p}<0.10,{ }^{* *} \mathrm{p}<0.05,{ }^{* * *} \mathrm{p}<0.01$. 


\section{Figures}

Figure A1: Estimated Impact on Cases of Malaria Comparison Across Specifications

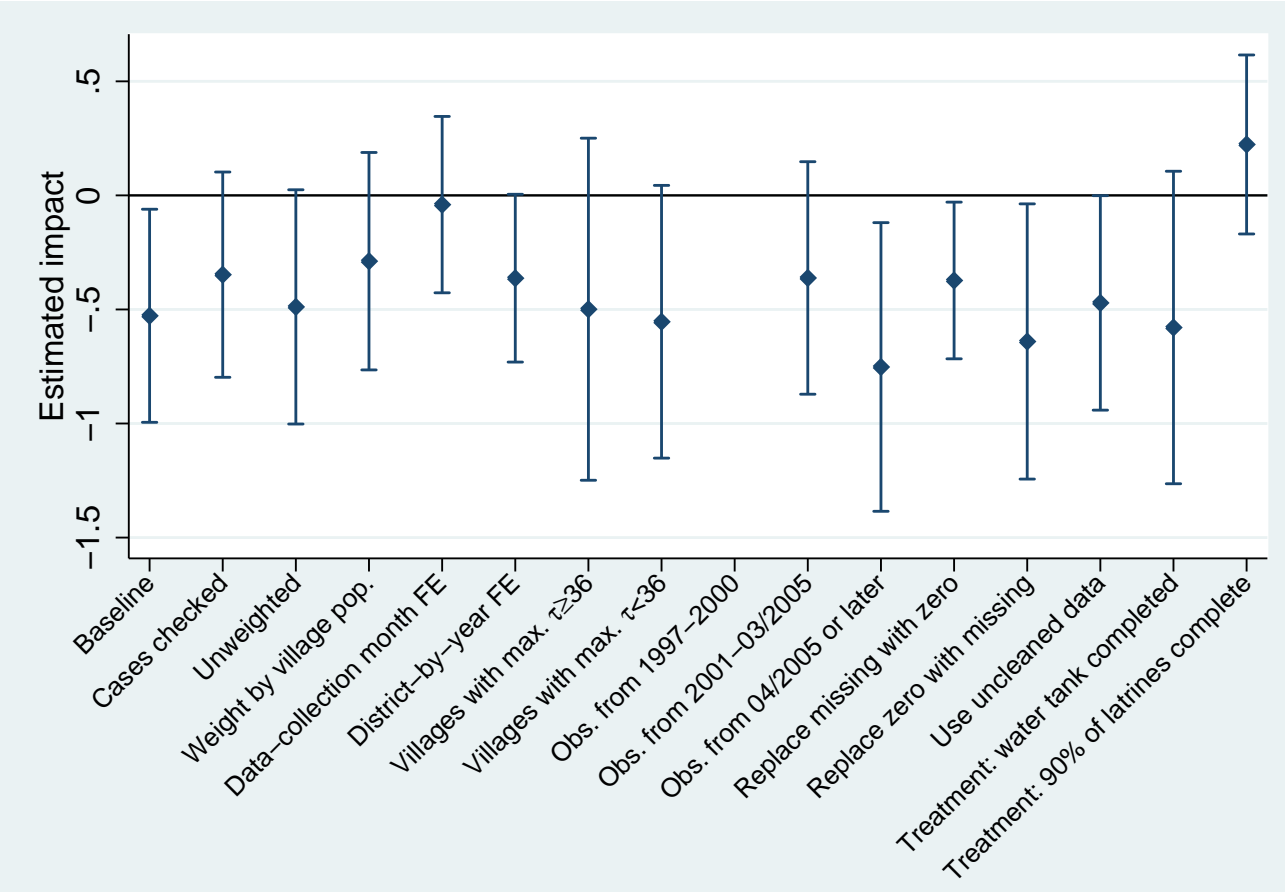

Notes: this figure reports estimated treatment effects, with $95 \%$ confidence intervals, for each of a series of variants on Equation (2) in the main text. The variant for each specification is described briefly by the label on the $\mathrm{x}$ axis, and in greater detail in the text of the Supporting Information. In all cases, the sample corresponds to Sample B in the main text, consisting of observations from two years before to five years after the initiation of services $(-24 \leq \tau \leq 59)$, and including only villages with at least six observations before and six observations after the initiation of services. Data on malaria were not systematically collected during the period 1997-2000, so that specification is excluded. All regressions include village and month-by-year fixed effects. Standard errors are clustered at the village level. 
Figure A2: Estimated Impact on Cases of Fever Comparison Across Specifications

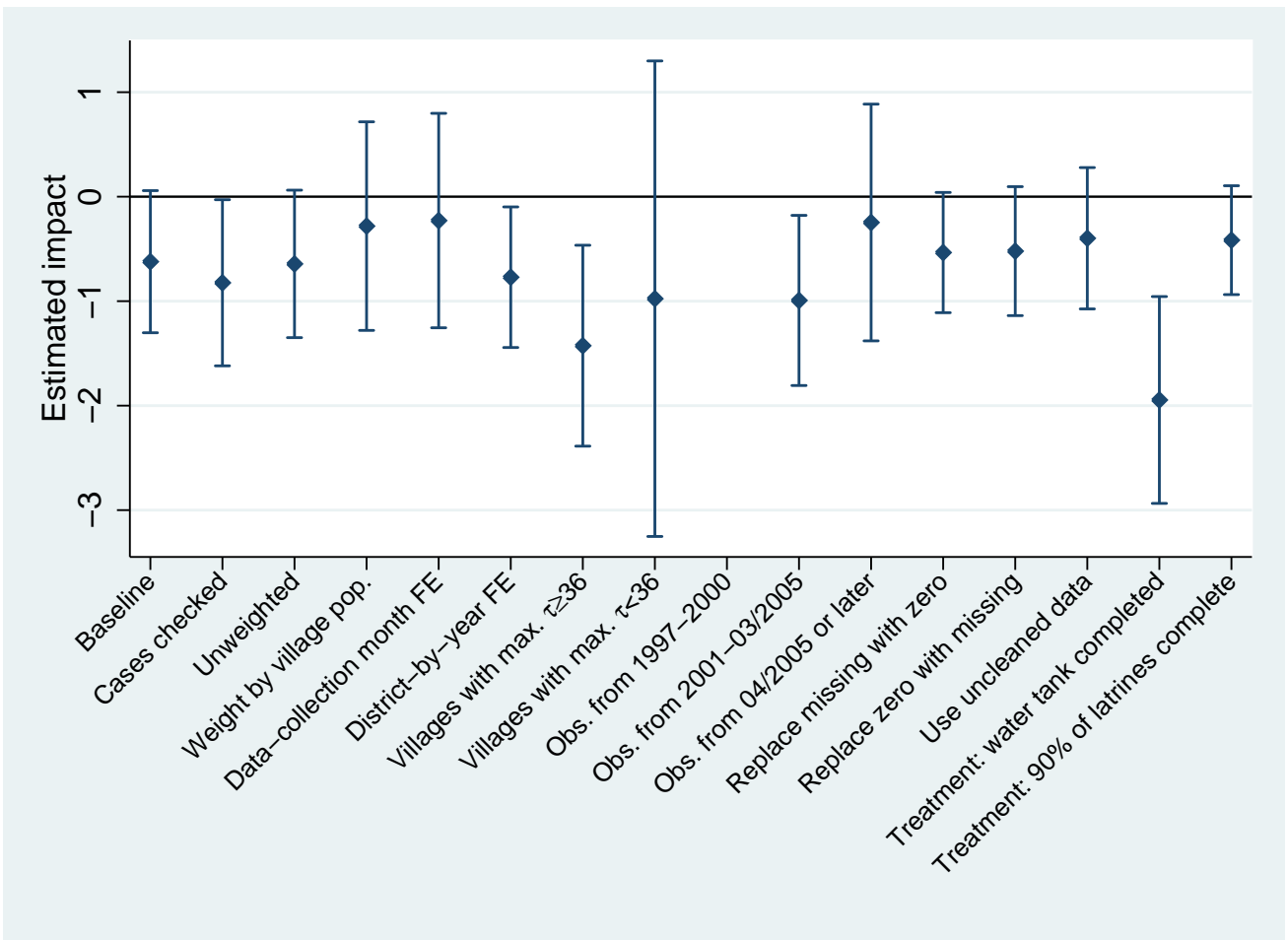

Notes: this figure reports estimated treatment effects, with $95 \%$ confidence intervals, for each of a series of variants on Equation (2) in the main text. The variant for each specification is described briefly by the label on the $\mathrm{x}$ axis, and in greater detail in the text of the Supporting Information. In all cases, the sample corresponds to Sample B in the main text, consisting of observations from two years before to five years after the initiation of services $(-24 \leq \tau \leq 59)$, and including only villages with at least six observations before and six observations after the initiation of services. Data on fever were not systematically collected during the period 1997-2000, so that specification is excluded. All regressions include village and month-by-year fixed effects. Standard errors are clustered at the village level. 


\section{Figure A3: The F-diagram}

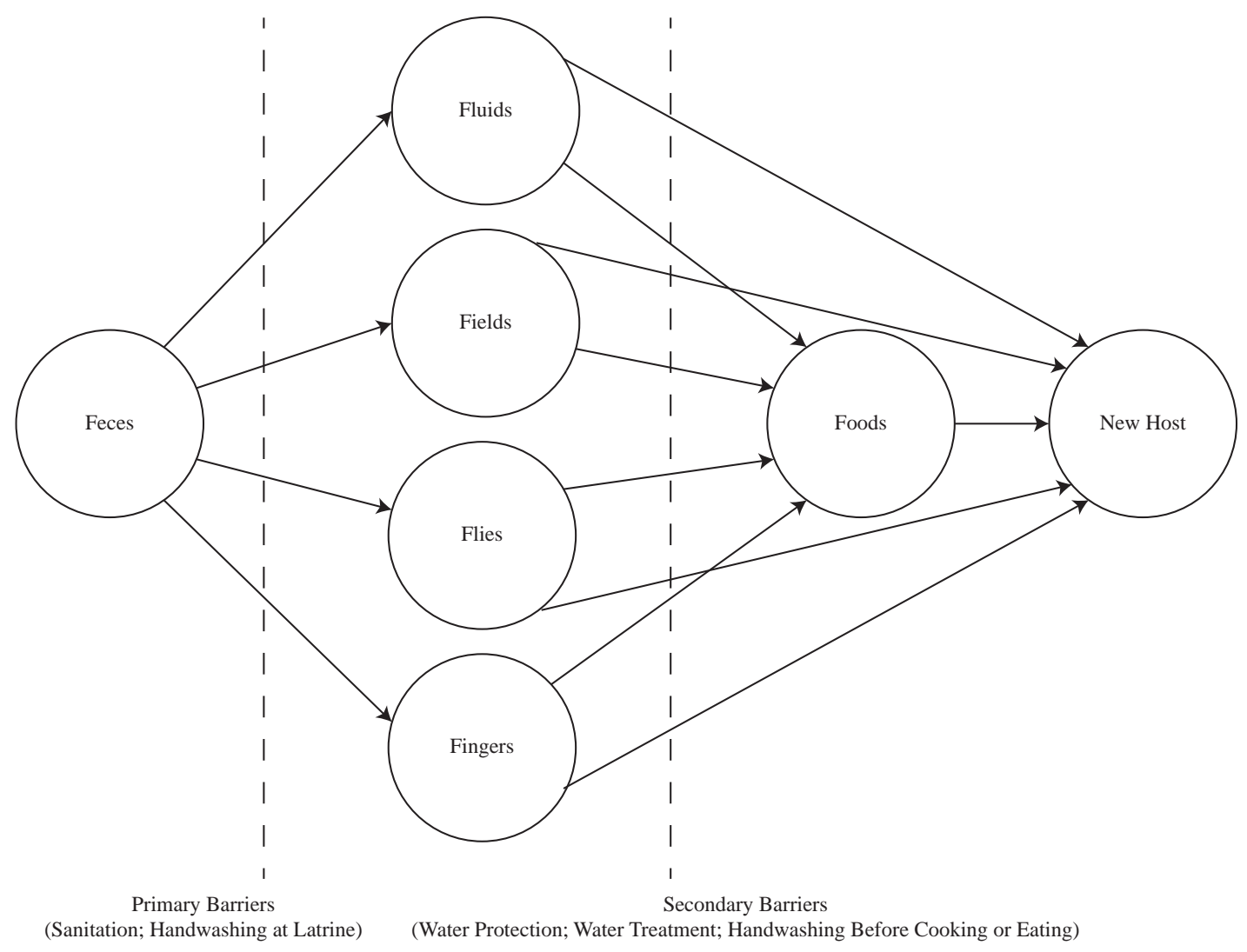

Notes: From Figure 1 of Curtis, Cairncross, and Yonli, 2000. 